\title{
Perforated Gastrointestinal Stromal Tumour of Jejunum
}

\author{
S. Shilpa Jain*, Kamalraj M, Ramalakshmi V, Kannan Ross
}

Institute of General Surgery, Madras Medical College and Rajiv Gandhi Government General Hospital, Chennai, Tamil Nadu, India

DOI: $10.36347 /$ sasjs.2020.v06i02.008

| Received: 06.02.2020 | Accepted: 13.02.2020 | Published: 18.02.2020

*Corresponding author: S. Shilpa Jain

Abstract

Case Report

A 62yr old diabetic male came to emergency department with complaints of abdominal pain and vomiting since 2 days. Physical examination details of patient was pale, dehydrated, had tachycardia and hypotension. Abdomen was distended and had diffuse tenderness and guarding. Free fluid abdomen was present, and bowel sounds were absent. Patient was resuscitated. USG done outside, revealed transverse colon growth. Radiological investigations revealed pneumoperitoneum with growth arising from small bowel. Patient was resuscitated and taken up for emergency laparotomy, which revealed a dumb-bell shaped mass arising from the jejunum with perforation. Resected specimen HPE showed GIST.

Keywords: Gastrointestinal stromal tumour, GIST, Jejunum, Perforation.

Copyright @ 2020: This is an open-access article distributed under the terms of the Creative Commons Attribution license which permits unrestricted use, distribution, and reproduction in any medium for non-commercial use (NonCommercial, or CC-BY-NC) provided the original author and source are credited.

\section{INTRODUCTION}

Gastrointestinal stromal tumors are the most common sarcomatous tumors of the GI tract. Malignant GISTs constitute for about $20 \%$ of malignant neoplasms of the small bowel. These tumors are more common in jejunum and ileum, diagnosed in the fifth and sixth decades of life. GISTs vary considerably in their presentation and clinical course, ranging from small benign tumors to massive lesions with necrosis, hemorrhage, and wide metastases, but rarely do they present with bowel perforation. In this journal we would like to discuss the points to be aware while managing such a scenario.

\section{CASE REPORT}

A 62 year old diabetic male came to emergency department with complaints of abdominal pain and vomiting since 2 days. Pain was described to be mild in nature, initially and gradually increasing in intensity, diffuse in nature. A few hours after the onset of pain he developed multiple episodes of vomiting which was bilious in nature. No history suggestive of obstipation. USG taken outside revealed growth arising from transverse colon with normal calibre of small and large bowel loops; suggested further evaluation with contrast CT abdomen.

On arrival, patient was afebrile, dehydrated and anemic. Tachycardia and hypotension was found. On examination the abdomen was distended with diffuse abdominal tenderness and guarding.

Patient was resuscitated with crystalloids, intravenous antibiotics were initiated and blood products were arranged. Following examination, hollow viscous perforation was suspected.

Following initial stabilization radiological investigations were taken. X-ray abdomen revealed pneumoperitonium. Abdominal CT scan revealed pneumoperitonium with growth measuring $10 \times 7 \times 15 \mathrm{~cm}$ arising from small bowel. Blood investigations revealed neutrophilia. Patient was planned for emergency laparotomy. 


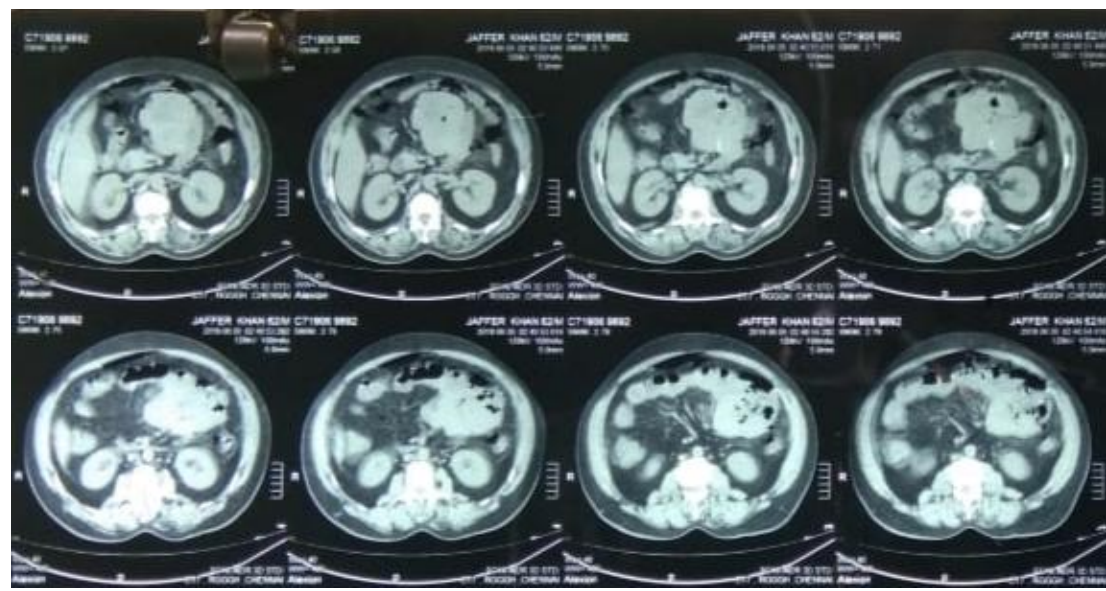

Fig-1: CT Abdomen showing pneumoperitonium with free fluid abdomen, ? growth arising from small bowel

Laparotomy revealed pneumoperitonium, 500 $\mathrm{ml}$ of sanguineous fluid along with a ruptured, highly vascular dumbell shaped growth approximately $10 \times 8 \times 15 \mathrm{~cm}$ arising from the proximal jejunum from the serosal surface in the mesenteric border. The ooze at the site of the rupture of the growth was arrested using monopolar diathermy. Through laparotomy was done to identify the site of perforation. On reflecting the growth and viewing the mesenteric border of the jejunum a $2 \times 1$ $\mathrm{cm}$ perforation was found.

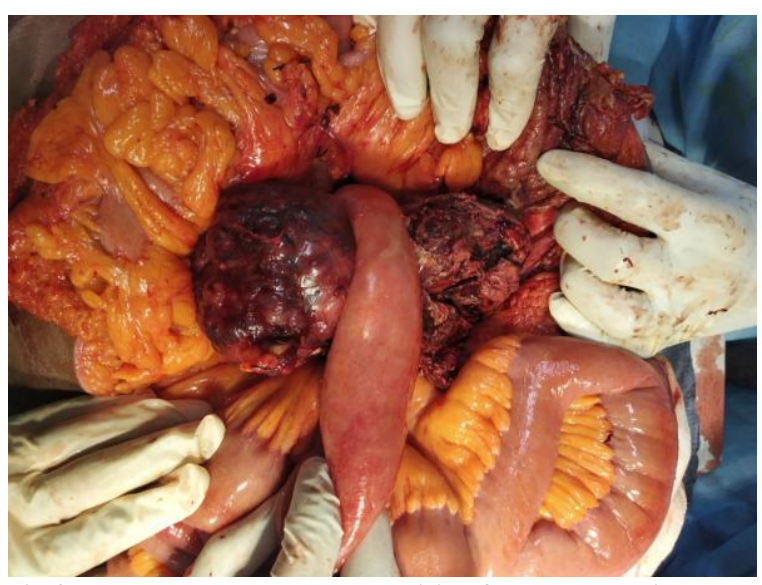

Fig-2: Dumbbell shaped growth arising from mesenteric border of jejunum $10 \mathrm{~cm}$ distal to DJ junction

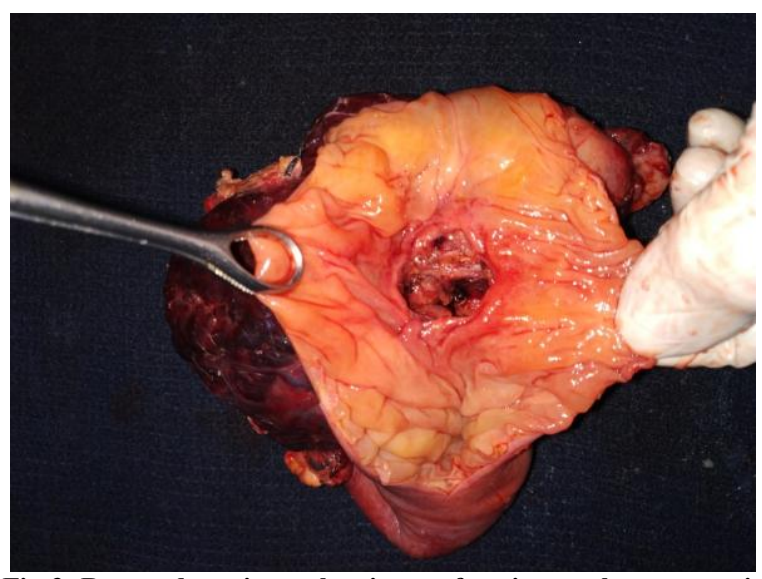

Fig-3: Resected specimen showing perforation on the mesenteric side of jejunum
The CT was revisited to look for vessel involvement. In view of no major vessel involvement, minimal contamination, and adequate proximal jejunum available following resection leaving a $5 \mathrm{~cm}$ margin we planned to go ahead with resection of the bowel segment with the growth and proceed with jejunojejunal anastomosis. Histopatology revealed it to be a jejunal GIST, diffusely positive for CD117. Patient succumbed to sepsis on post-op day 4 .

\section{DISCUSSION}

Gastrointestinal stromal tumors (GISTs) are the most common sarcomatous tumors of the GI tract derived from the interstitial cells of Cajal, an intestinal pacemaker cell. Although GIST can arise in any portion of the GI tract, from the esophagus to the rectum, the small bowel is the second most common site of involvement $(30 \%-40 \%)$, after the stomach $(40 \%-60 \%)$ [1].

Primary GIST arising in the GI tract presents symptomatically in $69 \%$ of cases, and is diagnosed incidentally at surgery in $21 \%$ of cases, with the remaining $10 \%$ found incidentally at autopsy [2].

The diagnosis of GIST of the small bowel may be delayed for several reasons, including its relatively low incidence, nonspecific and variable symptoms. The wide spectrum of radiological appearances, intestinal thickening, and the presence of overlapping loops of intestine make imaging studies difficult. All of above lead to delayed or misdiagnosis of GIST of the small bowel $[3,4]$.

\section{CLINICAL FEATURES}

Symptoms of GISTs at presentation may be related to mass effects. Mucosal ulceration can cause blood loss, and approximately half of individuals with GIST, present with anemia or related symptoms. GISTs may also be discovered as an incidental finding during radiologic imaging, endoscopy, or abdominal surgery performed for other reasons. 
The clinical symptoms associated with small bowel GIST are usually nonspecific and varied and are usually associated with tumor size and anatomical site. Jejunal GISTs, which comprise $10 \%$ of all GISTs [4], are usually symptomatic and patients suffer from abdominal pain and early satiety. They may also have symptoms secondary to obstruction or hemorrhage. Perforation with acute diffuse peritonitis is rare $[5,7$, $8]$.

Other relatively rare presentations of small bowel GIST include anemia, intraperitoneal hemorrhage and altered bowel motility [7, 9, 10]. Between $12 \%$ and $18 \%$ of patients with small bowel GIST have been reported to be asymptomatic, with the tumors detected incidentally $[2,11]$.

\section{INVESTIGATIONS}

The preoperative diagnosis of primary GIST of the small bowel is difficult to make due to the relative inaccessibility of the small bowel to conventional endoscopic examination. Also, it can be difficult to determine the nature of the mass solely on imaging of the abdomen. An abdominal ultrasound scan is often the initial imaging test employed in the investigation of a patient with abdominal pain or mass, but ultrasound is not an accurate method for the detection of tumors of the small bowel. CT imaging helps in diagnosing small bowel GIST and can be used for the detection, localization, staging, surgical planning, and in the evaluation of response to therapy. Although computer tomography is a viable imaging modality for patients suspected of having intra-abdominal GIST, magnetic resonance imaging modality provides a more accurate preoperative picture [12].

GISTs can be quite large, as much as $30 \mathrm{~cm}$ in diameter. They usually form a solitary, wellcircumscribed, fleshy mass covered by ulcerated or intact mucosa, but can also project outward toward the serosa.

The cut surface shows a whorled appearance. Metastases may take the form of multiple serosal nodules throughout the peritoneal cavity or as one or more nodules in the liver; spread outside of the abdomen is uncommon.

GIST composed of thin elongated cells are classified as spindle cell type, whereas tumors dominated by epithelial appearing cells are termed epithelioid type; mixtures of the two patterns also occur.

Tissue histology, supported by immunohistochemistry, is required for the definitive diagnosis of GIST.GIST tumors have variable markers, including C-KIT (CD 117), DOG-1, CD 34, SMA, S100, and Desmin, of which, they are almost always positive for C-KIT and DOG 1 [3, 13-16].
Approximately $75 \%$ to $80 \%$ of all GISTs have oncogenic, gain-of-function mutations in the receptor tyrosine kinase KIT. DOG1, a recently defined monoclonal antibody against a chloride channel protein expressed by GIST, is positively expressed in $95 \%$ of GISTs.

\section{MANAGEMENT}

Surgery is the standard treatment for nonmetastatic GIST [20]. The main objectives of surgical treatment are to achieve negative surgical resection margins (R0) and to resect the tumor without causing tumor rupture [20, 21]. A complete en bloc resection is recommended, whenever feasible, in cases where contiguous organs are involved [17, 20]. A laparoscopic approach in patients with large tumors is strongly discouraged. Radiologic criteria for unresectability include infiltration of the celiac trunk, superior mesenteric artery, or portal vein. Imatinib is a first-line standard therapy for unresectable, metastatic, or recurrent GIST, and the standard dosage is $400 \mathrm{mg} /$ day $[18,19]$

\section{PROGNOSIS}

Prognostic factors include anatomic location of the primary tumor, age at presentation, histomorphology, molecular genetics, and immunohistochemistry, of which tumor size is the most important [22].

\section{CONCLUSION}

- It is difficult to diagnose a jejunal GIST preoperatively due to the nonspecific and variable clinical symptoms, and it is also difficult to distinguish the tumor based solely on images.

- The definitive diagnosis of GISTs is revealed by histopathological examination of the specimen.

\section{Conflict of Interest: No}

\section{REFERENCES}

1. Joensuu H. Gastrointestinal stromal tumor (GIST). Ann Oncol. 2006;17(S10):x280-x286.

2. Nilsson B, Bümming P, Meis- Kindblom JM, Odén A, Dortok A, Gustavsson B, Sablinska K, Kindblom LG. Gastrointestinal stromal tumors: the incidence, prevalence, clinical course, and prognostication in the preimatinib mesylate era: a population- based study in western Sweden. Cancer. 2005 Feb 15;103(4):821-9.

3. Werewka-Maczuga A, Osiński T, Chrzan R, Buczek M, Urbanik A. Characteristics of computed tomography imaging of gastrointestinal stromal tumor (GIST) and related diagnostic problems. Polish journal of radiology. 2011 Jul;76(3):38-48. 
4. Xing GS, Wang S, Sun YM, Yuan Z, Zhao XM, Zhou CW. Small bowel stromal tumors: different clinicopathologic and computed tomography features in various anatomic sites. PLoS One. 2015;10(12):e0144277.

5. Miettinen M, Sobin LH, Lasota J. Gastrointestinal stromal tumors presenting as omental masses-a clinicopathologic analysis of 95 cases. The American journal of surgical pathology. 2009 Sep 1;33(9):1267-75.

6. Efremidou EI, Liratzopoulos N, Papageorgiou MS, Romanidis K, Manolas KJ, Minopoulos GJ. Perforated GIST of the small intestine as a rare cause of acute abdomen: surgical treatment and adjuvant therapy. Case report. Journal of Gastrointestinal and Liver Diseases. 2006 Sep;15(3):297-299.

7. Feng F, Chen F, Chen Y, Liu J. A rare perforated gastrointestinal stromal tumor in the jejunum: a case report. Turk J Gastroenterol. 2011 Apr 1;22(2):208-12.

8. Karaguelle E, Tuerk E, Yildirim E, Gõktürk HS, Kiyici H, Moray G. Multifocal intestinal stromal tumors with jejunal perforation and intraabdominal abscess: report of a case. Turk $\mathrm{J}$ Gastroenterol. 2008 Dec 1;19(4):264-7.

9. Feng F, Chen F, Chen Y, Liu J. A rare perforated gastrointestinal stromal tumor in the jejunum: a case report. Turk J Gastroenterol. 2011 Apr 1;22(2):208-12.

10. Karaguelle E, Tuerk E, Yildirim E, Gõktürk HS, Kiyici H, Moray G. Multifocal intestinal stromal tumors with jejunal perforation and intraabdominal abscess: report of a case. Turk J Gastroenterol. 2008 Dec 1;19(4):264-7.

11. Baheti AD, Shinagare AB, O'Neill AC, Krajewski KM, Hornick JL, George S, Ramaiya NH, Tirumani SH. MDCT and clinicopathological features of small bowel gastrointestinal stromal tumours in 102 patients: a single institute experience. The British journal of radiology. 2015 Sep;88(1053):20150085.

12. Amano M, Okuda $\mathrm{T}$, Amano $\mathrm{Y}$, Tajiri $\mathrm{T}$, Kumazaki T. Magnetic resonance imaging of gastrointestinal stromal tumor in the abdomen and pelvis. Clinical imaging. 2006 Mar 1;30(2):12731.

13. Miettinen M, Sarlomo-Rikala M, Lasota J. Gastrointestinal stromal tumours. InAnnales chirurgiae et gynaecologiae 1998; 87(4), 278-281.

14. Judson I. Gastrointestinal stromal tumours (GIST): biology and treatment. Annals of Oncology. 2002 Oct 1;13:287-9.

15. Hirota S, Isozaki K, Moriyama $\mathrm{Y}$, Hashimoto $\mathrm{K}$, Nishida T, Ishiguro S, Kawano K, Hanada M, Kurata A, Takeda M, Tunio GM. Gain-of-function mutations of c-kit in human gastrointestinal stromal tumors. Science. 1998 Jan 23;279(5350):577-80.

16. Corless CL, Fletcher JA, Heinrich MC. Biology of gastrointestinal stromal tumors. Journal of Clinical Oncology. 2004 Sep 15;22(18):3813-25.

17. Joensuu H. Gastrointestinal stromal tumor (GIST). Ann Oncol. 2006;17(S10):280-286.

18. ESMO/European Sarcoma Network Working Group Gastrointestinal stromal tumours: ESMO Clinical Practice Guidelines for diagnosis, treatment and follow-up. Ann Oncol. 2014;25(Suppl 3):iii21-iii26.

19. Nishida T, Blay JY, Hirota S, Kitagawa Y, Kang YK. The standard diagnosis, treatment, and follow-up of gastrointestinal stromal tumors based on guidelines. Gastric Cancer. 2016;19(1):3-14.

20. Kang YK, Kang HJ, Kim KM, Sohn T, Choi D, Ryu MH, Kim WH, Yang HK, Korean GIST Study Group. Clinical practice guideline for accurate diagnosis and effective treatment of gastrointestinal stromal tumor in Korea. Cancer research and treatment: official journal of Korean Cancer Association. 2012 Jun;44(2):85-96.

21. Koo DH, Ryu MH, Kim KM, Yang HK, Sawaki A, Hirota S, Zheng J, Zhang B, Tzen CY, Yeh CN, Nishida T. Asian consensus guidelines for the diagnosis and management of gastrointestinal stromal tumor. Cancer research and treatment: official journal of Korean Cancer Association. 2016 Oct;48(4):1155-1166.

22. Yan H, Marchettini P, Acherman YI, Gething SA, Brun E, Sugarbaker PH. Prognostic assessment of gastrointestinal stromal tumor. American journal of clinical oncology. 2003 Jun 1;26(3):221-8. 